\title{
MobileMech: Um Software Educacional para Apoiar o Processo de Ensino-Aprendizagem de Mecânica no Ensino Médio
}

\author{
Edmylson Junior, Heitor Costa
}

Departamento de Ciência da Computação - Universidade Federal de Lavras - Lavras - MG

edmylson.junioregmail.com, heitoredcc.ufla.br

\begin{abstract}
Resumo. Não é comum encontrar software educacional para apoiar o processo de ensino-aprendizagem em Física. Neste artigo, é apresentado um software educacional (MobileMech) desenvolvido para o ensino de temas abordados em Mecânica, um dos tópicos da matéria de Física, para alunos do Ensino Médio. MobileMech foi implementado para ser utilizado em um tablet com sistema operacional Android. Aprendizado que utiliza recursos apresentados em tablets e esteja inserido em contexto que os alunos estão habituados a aprenderem pode potencializar o ensino de Física. Os resultados da avaliação de uso mostraram que MobileMech tem potencial no contexto do processo de ensino-aprendizagem.
\end{abstract}

Abstract. Educational software to support teaching-learning process is rare. This paper presents educational software (MobileMech) developed for teaching Mechanics, related topic to Physics, for high school students. MobileMech was implemented for using in tablet with Android. Learning that using resources presented by a tablet and it is inserted in context that students are familiarized to learning can enhance the teaching of Physics. Results of use evaluating showed MobileMech has potential in context of teaching-learning process.

\section{Introdução}

A informática vem sendo considerada uma ferramenta de suporte para o processo de ensino-aprendizagem por profissionais da educação, de psicologia e de ciência de computação [Lazzarotto et al., 2011]. O uso da tecnologia aliada a educação vem se apresentando como um auxílio para o aprendizado além de incluir o aluno nas tecnologias disponíveis e motivando-os à busca do conhecimento. A utilização do computador junto ao quadro negro, professores e metodologias aplicadas ao processo de ensino-aprendizagem têm se mostrado um acelerador desse processo, proporcionando interação dos alunos com o conteúdo por meio de animações, visualizações e verificações [Oliveira et al., 2011].

Não é comum encontrar software para dispositivos móveis cujo objetivo está no processo de ensino-aprendizagem em tópicos relacionados à disciplina de Física. Dessa forma, o caráter lúdico que pode ser incorporado no uso de um tablet pode influenciar na motivação do aprendizado, tornando-o mais conciso. Além disso, é importante viabilizar a possibilidade de interações com outras mídias para dar suporte ao processo de ensinoaprendizagem, influenciar em aprendizado mais dinâmico, em que os alunos investigam o conteúdo, e aumentar o interesse pelo conhecimento científico, procurando informações em outras fontes.

Neste trabalho, o objetivo é apresentar um software educacional para o ensino de alguns temas abordados na Mecânica, um dos tópicos de Física, para auxiliar os alunos do Ensino Médio. Para isso, esse software foi implementado para tablets por acreditar que seu uso pode influenciar a forma do aluno encarar o processo de aprendizagem. 
O restante do artigo está organizado da seguinte forma. Conceitos e formas de utilizar a informática na educação são tratados na Seção 2. O software desenvolvido para tablets chamado MobileMech, em alusão a Mobile Mechanics, é mostrado na Seção 3. Resultados da avaliação são apresentados na Seção 4. Alguns trabalhos relacionados são resumidamente apresentados na Seção 5. Conclusões, contribuições e sugestões de trabalhos futuros são discutidas na Seção 6.

\section{Informática na Educação e sua Importância}

Encontrar computadores nas escolas é comum, mas tornou-se frequente após o enfoque no processamento de informações. Nos anos 80, a quantidade de computadores cresceu e as autoridades perceberam a influência que os computadores poderiam ter nas salas de aula. A questão cultural era frequentemente abordada como fator importante para o projeto de um software educacional. Na Austrália, houve interesse de empregar computadores para funções educacionais, tendo como ênfase a questão cultural, pois se acreditava que o fato do software ser desenvolvido localmente era fundamental para a implantação e o sucesso de software educacional [Tatnall; Leonard, 2010].

Existem algumas defesas de que os melhores métodos de ensino e de aprendizado serão por meio do uso de computadores. Por outro lado, há severas críticas em que os computadores são vistos como intrusos no currículo e não como uma inevitável consequência do progresso tecnológico. O questionamento é se um software pode abstrair o conhecimento ou apenas criar estereótipos; outros questionamentos são a respeito da formação de indivíduos que se isolam e são passivos em demasia [Moreno; Marquéz, 2008]. Independente das questões levantadas a respeito do uso de computadores para o ensino, as possibilidades encontradas com eles têm sido exploradas e a teoria da informática na educação tem sido aplicada. Uma das definições teóricas importantes é o $\mathrm{m}$ learning que consiste na capacidade do uso de dispositivos portáteis para acessar recursos de aprendizagem [Kinshuk et al. 2003]. O m-learning é extensão do e-learning para dispositivos móveis, sendo uma entidade que disponibiliza informação digital e capaz de adequar-se em diferentes contextos. M-learning deve permitir acesso à aprendizagem em qualquer lugar e hora e simular situações de aprendizagem, permitindo ao aluno participar no processo [Rachid; Ishitani, 2012; Brown, 1989].

Uma das razões para utilizar dispositivos móveis no ensino é a possibilidade de aproveitar o tempo improdutivo quando um estudante está a caminho da escola ou a outro local ou esperando por algo. O uso de software educacional em dispositivos móveis podem contribuir para o aprendizado [Liu et al., 2010]. Em pesquisa sobre a utilização desses dispositivos no aprendizado, a maioria sentiu-se confortável, aprovando seu uso em salas de aula [Uzunboylu et al., 2009].

\section{Software Educacional MobileMech}

MobileMech é um software educacional desenvolvido para dispositivos móveis para o ensino de alguns temas abordados na Mecânica, um dos tópicos de Física, para alunos do Ensino Médio, sendo uma das características não proporcionar completa independência de um tutor. No MobileMech, há conhecimento teórico apresentado em capítulos para tornálo mais adequado ao ensino. Para o seu desenvolvimento, foram utilizados Android SDK, que oferece APIs e ferramentas utilizadas para construção, teste e debug, IDE Eclipse e um emulador virtual disponível no kit de desenvolvimento. Os conceitos abordados são Força, 
Força Gravitacional, Força Normal, Força de Atrito, Resistência do Ar, Impulso de uma Força, Quantidade de Movimento, Leis de Newton, Energia Cinética, Energia Potencial Gravitacional, Conservação da Energia Mecânica e Trabalho. Há breve explanação sobre esses conceitos para possibilitar o seu uso adequado e três tipos de atividades interativas, as quais o aluno tem que executar. A primeira atividade diz respeito à explicação teórica de conceitos (Figura 1). A segunda atividade consiste na experimentação do conceito apresentado (Figura 2). A terceira atividade é um jogo no qual o aluno tem que aplicar o que foi aprendido para completar um objetivo (Figura 3).

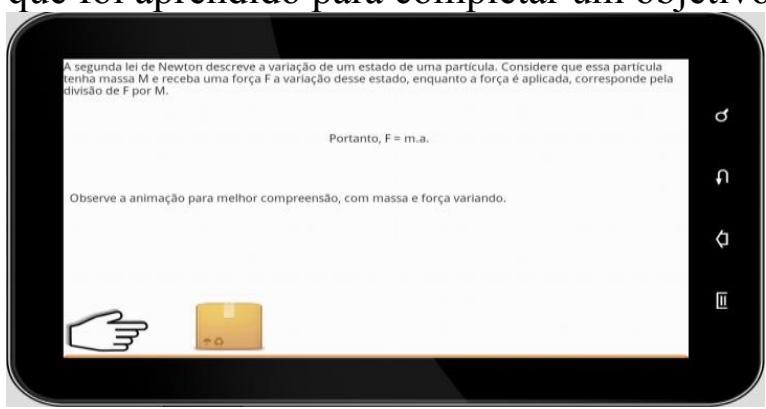

Figura 1 - Exemplo da Primeira Atividade

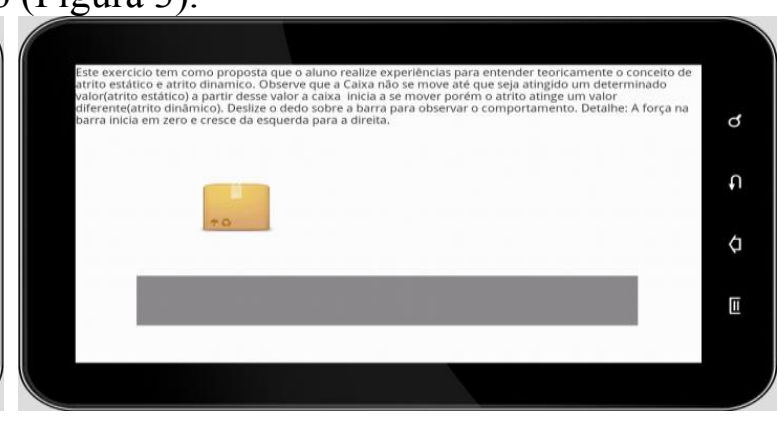

Figura 2 - Exemplo da Segunda Atividade

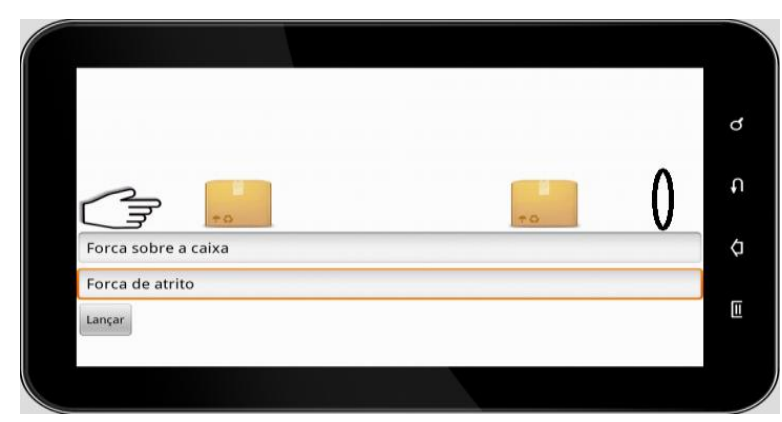

Figura 3 - Exemplo da Terceira Atividade

A primeira atividade é apresentada de forma textual, cujo texto é simples e direto para evitar que a leitura torne-se enfadonha ou cansativa, podendo haver animações para exemplificar o texto. O conteúdo não ocupa mais do que uma tela (não há rolagem de tela), salvo raras exceções. Com isso, acredita-se que a interação do usuário fique menos cansativa proporcionando melhor aproveitamento do tempo. Na segunda atividade, a ideia é o aluno ter um laboratório virtual em que ele possa realizar experimentações necessárias para verificar/sedimentar um conceito. Essa atividade é altamente interativa para o aluno fazer inferências como são feitas na prática. Caso necessário, cabe ao professor aguçar as inferências e/ou separar as que sejam relevantes impedindo compreensão errada da teoria. $\mathrm{Na}$ terceira atividade, o objetivo é aplicar o que foi aprendido realizando exercícios. Buscase semelhança com os jogos de computadores, nos quais os alunos sentem-se motivados para alcançar o objetivo proposto. Essa atividade é baseada nos benefícios que o caráter lúdico de um jogo de computador pode proporcionar no processo de ensino-aprendizagem.

\subsection{Cenários de Explanação Teórica}

$\mathrm{Na}$ explanação teórica, o objetivo é apresentar aos usuários a teoria para melhorar a compreensão de outros cenários em que os conceitos físicos são descritos textualmente; para isso, buscou-se usar linguagem menos formal. São usadas metáforas para elucidar situações cotidianas que têm relações diretas com o conteúdo abordado. 
No cenário da Figura 4, é apresentada teoria referente à Força e à Capacidade de uma Força causar alteração de um estado inicial para um estado final. Esse estado inicial é definido como o estado de estar brincando. O usuário é lembrado de uma situação comum e, possivelmente, vivenciada. No cenário da Figura 5, é discutido o conceito de Inércia. $\mathrm{O}$ objetivo é o usuário compreender que um objeto tende a permanecer em um estado até acontecer algum evento que afete esse estado. Além desses cenários, há cenário que apresenta o conceito de Trabalho e Energia. Inicialmente, o usuário é estimulado a lembrar de uma situação, por exemplo, uma explosão, e é realizado um paralelo entre explosão e energia. Em seguida, é explicado o que uma explosão pode vir a causar e é discutida a variável força nesse processo de explosão responsável por uma consequência, sem mencioná-la formalmente. Além desses, há outros cenários que, por causa de espaço, não são apresentados, mas podem ser vistos em [Silva Júnior, 2013].

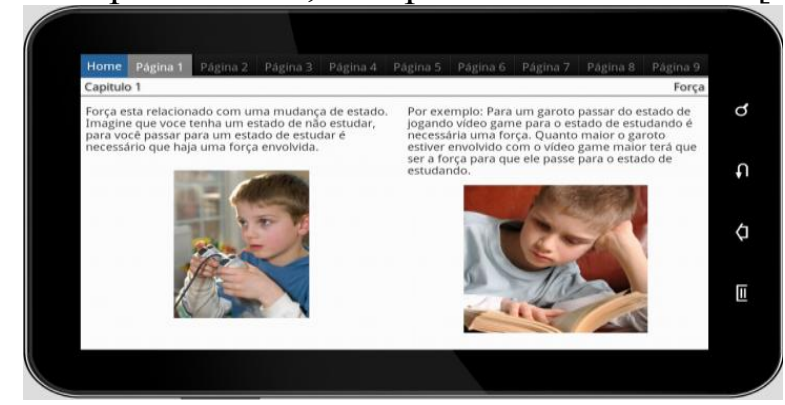

Figura 4 - Cenário 1

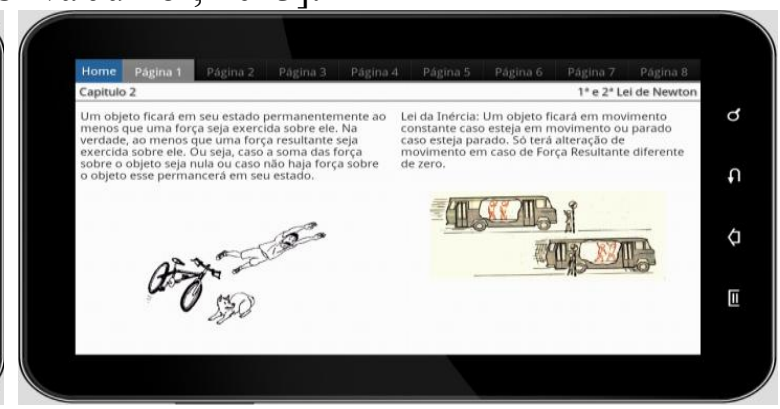

Figura 5 - Cenário 2

\subsection{Cenários de Experimentação}

Nesses cenários, o objetivo é o usuário fazer experimentos usando conceitos apresentados na Explanação Teórica. Em um desses cenários (Figura 6), o objetivo é o usuário experimentar as variáveis força e massa. Na parte superior, é apresentado breve enunciado explicando o que se pretende abordar nessa experimentação. A barra de força e de massa são as que não apresentam valor numérico; assim, o usuário precisa preencher as barras em uma proporcionalidade adequada ao que ele pretende fazer. Ao selecionar o botão Lançar, a velocidade da caixa é calculada. Desse modo, o usuário pode observar o comportamento da caixa após a aplicação de uma força em determinado tempo. O fato do usuário não ser informado sobre os valores numéricos de força e massa é para ele concentrar-se na proporcionalidade entre as variáveis envolvidas no experimento.

No cenário da Figura 7, o objetivo é o usuário experimentar o conceito de Atrito. Na parte superior, é apresentado um enunciado a respeito do que se trata esse experimento. A caixa ao meio é o objeto que faz parte desse experimento. A barra na parte inferior da tela é uma de força cuja magnitude cresce da esquerda para a direita. É proposto ao usuário realizar uma força sobre a caixa utilizando a barra de força. A força é aplicada na direção horizontal e sentido da esquerda para a direita. A proposta é essa força iniciar em zero e ser aumentada gradualmente. A partir do momento que a força atinja determinado valor, o objeto começa a se mexer. O movimento é retardado quando uma força menor é aplicada ao objeto. Com isso, espera-se que o usuário perceba os conceitos de atrito e as particularidades de atrito estático e atrito dinâmico.

Além desses, há outros cenários que abordam alteração de variáveis (massa, gravidade e grau de inclinação da superfície), permitem observar que o comportamento de um objeto se altera quanto há atuação de uma força resultante diferente de nula, 
auxiliam a compreensão do trabalho realizado por uma força para acelerar um objeto, abordam a relação entre Trabalho e Energia Cinética com demonstração da possibilidade da energia transformar-se em trabalho exercido por uma força e clareiam o conceito de Energia Potencial com um exemplo de arco e flecha. Infelizmente, por causa de espaço, esses cenários não são apresentados, mas podem ser vistos em [Silva Júnior, 2013].

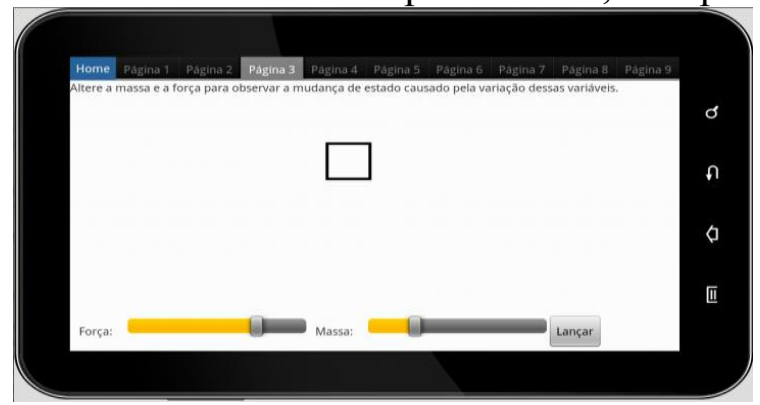

Figura 6 - Cenário 5

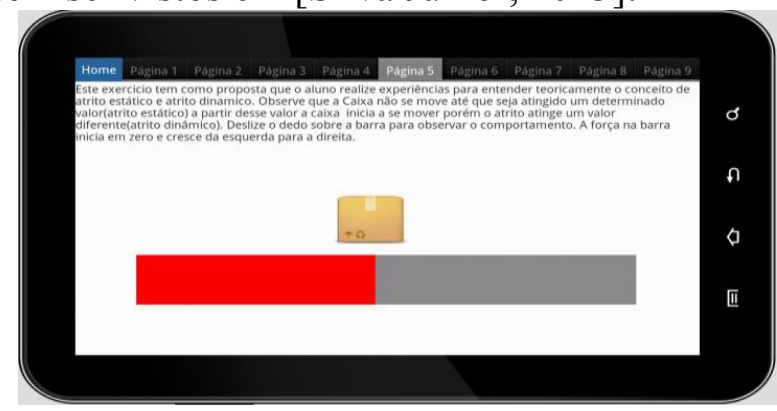

Figura 7 - Cenário 6

\subsection{Cenários de Exercitação}

No cenário da Figura 8, o objetivo é o usuário exercitar o conceito da influência da força Peso no objeto em um plano inclinado. Na parte superior da tela, são apresentadas variáveis para execução do exercício; nas laterais, há um conjunto de planos com inclinações diferentes e com um objeto no qual o usuário interage; no meio, há uma máquina que indica qual é o plano selecionado e as informações que influenciam na execução da tarefa, tais como, gravidade e massa do objeto, além de tempo para execução da tarefa. Na parte inferior da tela, há uma barra de força. O usuário é motivado a fazer o cálculo correto para que a força resultante aplicada sobre o objeto, paralelamente ao plano, seja (próxima de) nula. Em seguida, o usuário precisa aplicar essa força fazendo uso da barra de força. A força aplicada é paralela ao plano e tem direção e sentido do movimento inicial do objeto. Posteriormente, o objeto move-se em velocidade constante até o meio do percurso; para ele continuar o movimento, o usuário deve aplicar a força necessária para manter a força resultante igual a (próximo de) zero.

No cenário da Figura 9, o objetivo é o usuário realizar exercícios abordando o conceito de impulso. Na parte superior da tela, há um enunciado com a descrição do exercício e variáveis que influenciam a sua realização; no meio, há uma bola, com a qual o usuário interage, e um alvo; e, na parte inferior, há variáveis a serem alteradas (força a ser exercida sobre a bola e tempo de aplicação dessa força). O usuário deve alterar essas variáveis e "lançar" a bola para observar o impacto do impulso aplicado na bola. Assim, um impulso na direção horizontal e de sentido da esquerda para a direita é realizado sobre a bola implicando em movimento. O usuário precisa colocar a bola sobre o alvo. Quanto maior a precisão, maior a pontuação. Além desses, há outros cenários que permitem ao usuário realizar exercícios abordando o conceito de quantidade de movimento e perceber a variação de quantidade de movimento. Infelizmente, por causa de espaço, esses cenários não são apresentados, mas podem ser vistos em [Silva Júnior, 2013].

\section{Avaliação}

MobileMech foi avaliado utilizando um questionário elaborado com o qual avaliadores responderam afirmações escolhendo entre as opções Concordo Plenamente, 
Concordo, Discordo e Discordo Plenamente. O questionário abordou questões de qualidade da navegação, interface gráfica, usabilidade, contribuição para o estudo de física, se a teoria é bem apresentada, se as experimentações são adequadas e se os desafios são adequados. Além disso, havia espaço reservado para sugestões adicionais no qual os avaliadores poderiam emitir alguma opinião. Foi desenvolvido um roteiro de uso do MobileMech para motivar os avaliadores a realizar algumas atividades.

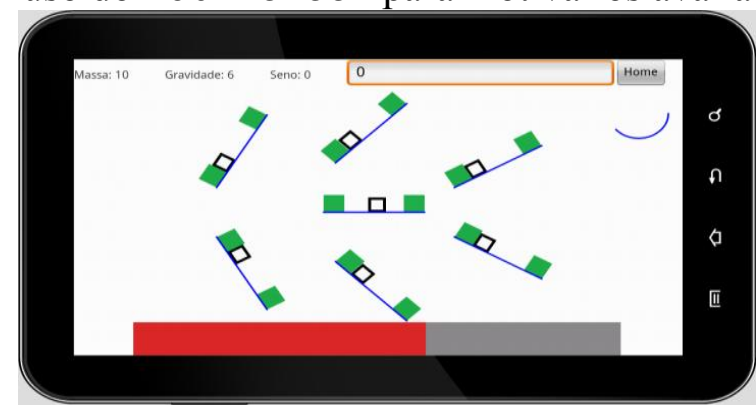

Figura 8 - Cenário 12

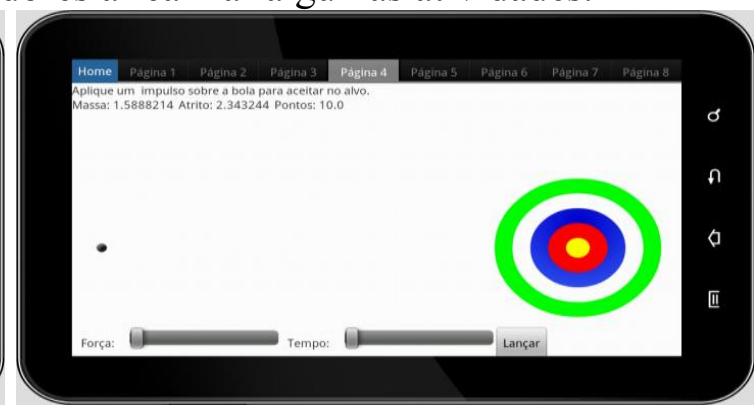

Figura 9 - Cenário 13

Os avaliadores foram alunos do curso de licenciatura em Física de uma Instituição de Ensino Superior que consideraram a interface objetiva. Não houve dificuldades em entender o que era preciso fazer para que o MobileMech fizesse o que eles pretendiam. Os desenhos foram considerados parcialmente intuitivos. Acredita-se que isso é por causa dos recursos disponibilizados pela a API utilizada não serem suficientes para desenhar objetos precisamente fiéis e atrativos ao que representam. Porém, os avaliadores disseram que MobileMech apresentou usabilidade suficiente para alcançarem seus objetivos com efetividade e eficiência (Figura 10).

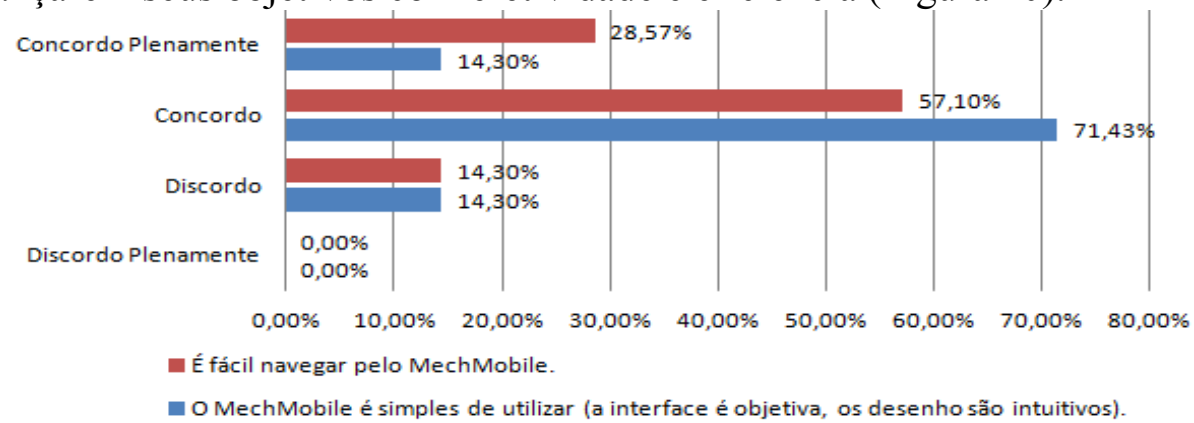

Figura 10 - Usabilidade do Mobi leMech

MobileMech é divido em três atividades as quais o usuário precisa executar: i) Teoria; ii) Experimento; e iii) Exercício (desafio). A respeito da Teoria, os avaliadores disseram que a linguagem apresentada é diferente do que é utilizado para o ensino de Física. Eles acharam que por ser um software para dispositivos móveis a linguagem é adequada. Houve aceitação com relação à forma que a teoria é descrita. Os avaliadores disseram que as analogias e a informalidade inicial na apresentação da teoria contribuíram para essa atividade ser prazerosa. Houve preocupação no desenvolvimento, por causa da forma com que o usuário interage com essa atividade comprometer o ritmo que MobileMech pretendia impor. Foi verificado que essa atividade obteve boa aceitação. Em relação aos Experimentos, os avaliadores relataram que eles estão bem relacionados com o que foi apresentado na teoria. Além disso, acharam estimulante verificar os conceitos representados e comentaram que a relação entre experimentos e exercícios é importante no sentido de melhor compreensão da 
teoria. Entretanto, houve "pequena" discordância em relação à possibilidade dos experimentos ajudarem nos exercícios. Alguns não acharam que os experimentos contribuem de forma direta para realização dos exercícios.

A respeito dos Exercícios (desafios), os avaliadores ficaram motivados a resolvê-los e sentiram-se estimulados a continuarem realizando essa atividade. Entretanto, houve "pequena" discordância em relação ao texto que introduz essa atividade. Alguns disseram que o texto poderia ser mais explicativo, pois gastariam menos tempo para compreender como realizar algumas tarefas. Porém, foi verificado que, após curto espaço de tempo, os avaliadores dominavam os cenários relativos aos exercícios. Acredita-se que a aprendizagem demande tempo mesmo com um texto mais explicativo e um texto muito explicativo pode tornar a compreensão maçante. Além disso, foi observado que, à medida que o avaliador realiza um exercício, o próximo era mais facilmente compreendido.

As respostas das perguntas relacionadas ao grau de aceitação dos participantes dos cenários de teorização, experimentação e exercitação são apresentadas na Figura 11. As perguntas referem-se ao grau de aceitação da teorização, da experimentação e da exercitação. Os avaliadores não concordaram plenamente que a ordem de execução das tarefas, da forma como foi apresentada, influencie na aprendizagem do aluno. Alguns consideraram desnecessário que seja feito experimentos para realização dos exercícios e disseram que a aprendizagem poderia ser abreviada. Outros relataram o contrário, para esses os experimentos, são fundamentais os exercícios para complementar a aprendizagem.

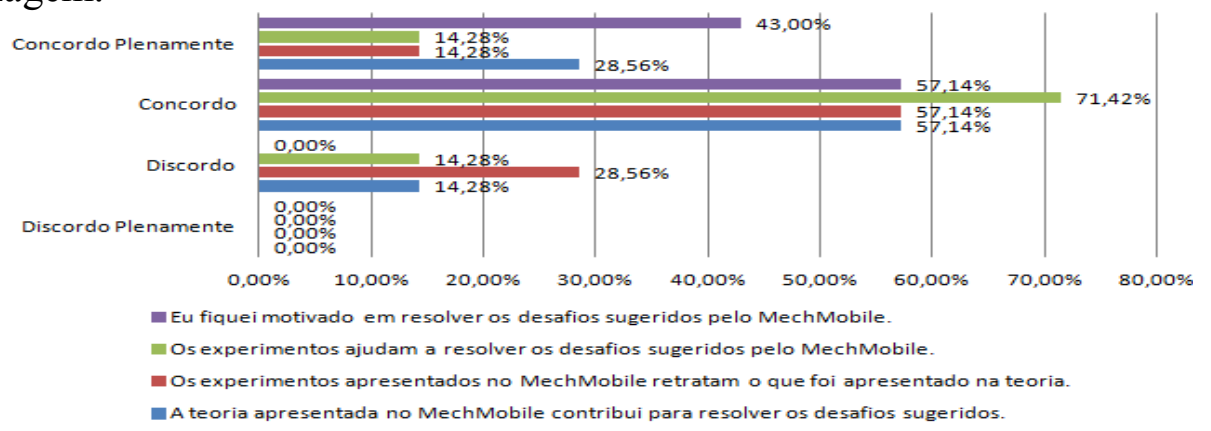

Figura 11 - Aceitação dos Cenários do MobileMech

Houve sugestões adicionais. Um dos avaliadores disse que vetores poderiam ter sido mais bem utilizados para representar movimento. Para esse avaliador, algumas vezes não ficou claro a direção e o sentido de uma força aplicada sobre um objeto. Outros consideraram pouco o tempo para realizar alguns exercícios. Outros disseram que as fórmulas poderiam estar mais bem posicionadas na tela na apresentação da teoria. Um dos avaliadores disse que a apresentação dos conceitos poderia ser mais formal. Os avaliadores disseram que indicariam MobileMech para algum amigo e o utilizariam como ferramenta de apoio em sala de aula. Houve unanimidade a respeito da possibilidade do MobileMech contribuir para o ensino de Física (Figura 12).

\section{Trabalhos Relacionados}

Em decorrência da dificuldade dos alunos de Física entender fenômenos abstratos ou com poucas referências de conhecimentos adquiridos nos ambientes em que eles se encontram, um iniciativa para auxiliar o processo de ensino-aprendizagem [Anderson; 
Barnett, 2010] propôs o jogo Supercharged!. Seu objetivo é auxiliar nesse processo apresentando abstrações e utilizando tecnologia computacional disponível. Além do caráter imersivo, é relatado que o jogo tem um alto nível de interação e possui caráter experimental no sentido de apresentar os princípios sobre disciplinas de Física com experiências utilizadas em laboratórios. Os temas são referentes ao eletromagnetismo.

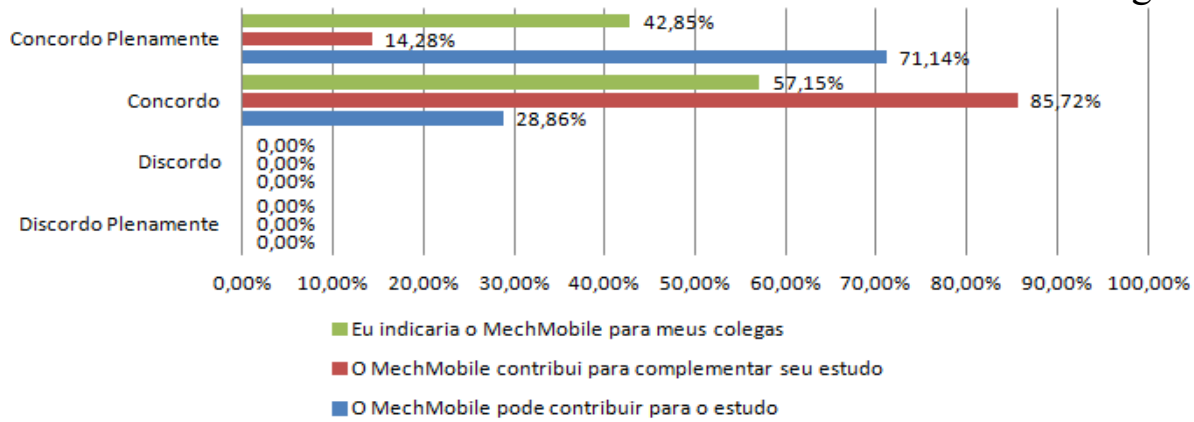

Figura 12 - Aceitação do Mobi leMech para Apoiar o Processo de Ensino-Aprendizagem

Há iniciativas que extrapolam o contexto da Física, mas com o intuito de contribuir no processo de ensino-aprendizagem em diversos tópicos. Em uma dessas iniciativas [Brom et al., 2009], há o relato do jogo multiplayer Europe 2045, em que cada estudante representa um membro da União Europeia. O jogo possibilita ao estudante estruturar conhecimento e desenvolver habilidades de criar modelos mentais, além de propiciar o relacionamento desses conhecimentos com outros. Além disso, combina princípios de dois gêneros dos jogos: multi-player on-line e role-playing games. Estudantes do ensino fundamental regularmente possuem dificuldades para entender representações numéricas. A fim de tornar a compreensão mais simples e interessante foi proposto um jogo [Lindström et al., 2011] para o aprendizado sem relacionar diretamente ao ensino tradicional desse conteúdo. $\mathrm{O}$ jogo é baseado em uma metáfora para aritmética, em que os números são objetos gráficos e as operações aritméticas são as ações entre estes objetos. O jogo possui modos multi-players que podem ser colaborativos ou competitivos.

Em outro trabalho [Heck, 2009], é apresentado um jogo chamado Coach que consiste em um ambiente computacional no nível escolar primário e secundário que oferece a estudantes e professores versatilidade em ferramentas integradas para a coleta de dados. O seu objetivo é construir, simular e validar modelos computacionais no ensino de Física, Matemática e Ciências. Em uma pesquisa no ensino de trigonometria [Ross et al., 2011], foi identificada a necessidade de conduzir o aprendizado em um novo formato; para isso, foi proposta a utilização de objetos de aprendizado. Nessa pesquisa, revelou-se que essa utilização, após os estudantes terem sido introduzidos na disciplina, proporciona melhor compreensão do conteúdo, mas não obteve diferenças estatísticas de acordo com um teste aplicado. No estudo qualitativo, notou-se que os alunos estavam habituados a utilizar artifícios que funcionavam bem com os tipos de exercícios empregados, mas que não apresentavam de fato o conteúdo. Os alunos resolviam os problemas, mas não sabiam o que estavam fazendo. O software se chama CLIPs:Trig e seu objetivo é definir funções trigonométricas com exemplos práticos.

Este trabalho difere-se dos outros por ser desenvolvido para um dispositivo móvel tendo como objetivo proporcionar maior flexibilidade ao aluno em relação ao local de aprendizagem. Além disso, buscou-se desenvolver o software considerando três aspectos base: i) ter finalidade unicamente teórica, apresentando textos, vídeos ou 
recursos sonoros para transmitir o conhecimento; ii) apresentar experimentos físicos para o aluno realizar experiências virtuais e verificar o que foi aprendido; iii) estimular a retenção do conhecimento aprendido com jogos. Apesar dos trabalhos relacionados apresentarem esses aspectos, eles não apresentam conjuntamente uma estrutura para $o$ ensino do conteúdo.

\section{Considerações Finais}

A utilização de um software educacional para dispositivos móveis em sala de aula pode contribuir para o processo de ensino-aprendizagem, pois os alunos podem ficar motivados com essa "novidade". O grau de interatividade proporcionado por esses dispositivos faz com que os alunos concentrem-se e executem as tarefas propostas tendo em vista que o interesse pela aprendizagem dos conceitos abordados cresce e o usuário sente-se estimulado a aplicá-los e adquirir maturidade sobre a teoria aprendida. Com MobileMech, não há pretensão de ensinar sem o auxílio de um tutor, pois podem existir questionamentos dos alunos não possíveis de serem sanados, não porque não são abordados, mas pela perspectiva única que cada aluno pode apresentar sobre um determinado assunto. Assim, o tutor tem sua importância no processo de ensinoaprendizagem por ter habilidade para tratar esses assuntos em pontos de vistas diferentes. A elaboração de cenários interativos que respondam a diversos parâmetros foi necessária. Os cenários precisavam estar conectados aos tópicos abordados de tal forma que o conceito físico apresentado seja encontrado pelo usuário implicitamente. Dessa forma, o usuário faria observações com maior fluência sem necessidades de explicação prévia do que se trata cada cenário. Pode-se concluir que tal esforço contribuiu para tornar MobileMech atrativo e o processo de ensino-aprendizagem fluir com poucas interrupções para fazer explanações ao usuário.

$\mathrm{Na}$ avaliação, os avaliadores que testaram MobileMech ficaram motivados em utilizá-lo. Eles acharam MobileMech útil no processo de ensino-aprendizagem e aplicável em sala de aula, concordaram que a organização do texto, do experimento e dos exercícios facilitam o processo e, por se tratar de um software móvel, informaram que MobileMech é atrativo. Diante disso, pode-se concluir que MobileMech pode potencializar a processo de ensino-aprendizagem dos assuntos abordados em Física. MobileMech foi desenvolvido para proporcionar aprendizagem agradável e ressalta-se a necessidade de complementar esse aprendizagem com a presença de um tutor para responder indagações de alunos. Com MobileMech, pode-se proporcionar e incentivar o amadurecimento dos conceitos após a aprendizagem. Dessa forma, espera-se que o aluno possa encontrar respostas aos seus anseios em relação aos tópicos abordados.

Esse trabalho possui algumas limitações. Dentre elas, a principal é atentar a necessidade de disponibilizar mais cenários interativos para disponibilizar ao usuário uma quantidade maior de interatividade o que implicaria em aceitação melhor do MobileMech. Também, há limitações a respeito do escopo coberto da disciplina de Mecânica. Poderia ter sido coberto outros conteúdos, fornecendo material mais completo. Entretanto, esse trabalho procurou focar nos tópicos mais importantes para compreensão da Mecânica. Existem limitações de interface que pudem abranger parte dos recursos disponíveis para um dispositivo móvel. MobileMech poderia fazer uso mais amplo dos recursos gestuais na tela disponíveis nesses dispositivos. Acredita-se que isso pode contribuir para interatividade mais intensa. Dessa forma, o usuário 
interagiria de maneira mais natural com o software. Além disso, há limitações na qualidade gráfica. O MobileMech poderia apresentar imagens de objetos de animações com mais detalhes em seus desenhos, com cores melhores relacionadas.

Como sugestões de trabalhos futuros, podem-se desenvolver módulos para abranger outros tópicos de Mecânica, desenvolver módulos para outros assuntos de Física; revisar o MobileMech por realizar pesquisas e estudos de frameworks para auxiliar o desenvolvimento de animações e minijogos mais atraentes, inserir efeitos sonoros para melhorar a experiência durante a realização das tarefas propostas no MobileMech, desenvolver um sistema de ranking de pontuação para os desafios. Assim, um usuário poderia comparar o seu desempenho com outros colegas, desenvolver um módulo para conectar-se a Web, disponibilizando recursos adicionais durante o processo de aprendizagem e desenvolver desafios para multijogadores on-line.

\section{REFERÊNCIAS BIBLIOGRÁFICAS}

Anderson, J.; Barnett, M. Using Video Games to Support Pre-Service Elementary Teachers Learning of Basic Physics Principles. In: Journal of Science Education and Technology. V. 20. pp. 347-362. 2011.

Brom, C.; Sisler, V.; Slavík, R. Implementing Digital Game-Based Learnig in Schools: Augmented Learning Environment of 'Europe 2045'. In: Multimedia System. V. 16. pp. 2341. 2009.

Brown, J. S.; Collins, A.; Duguid, P. A. An Architecture for Mobile Learning Objects. In: IEEE Multidisciplinary Engineering Education Magazine. V. 18. pp. 32-42. 1989.

Heck, A. Bringing Reality into the Classroom. In: Teaching Mathematics Applications. V. 28. pp. 164-179. 2009.

Kinshuk, S.; Jarkko, S.; Erkki, G. T. Mobile Technologies in Support of Distance Learning. In: Asian Journal of Distance Education. V. 1. pp. 60-68. 2003.

Lazzarotto, L. L.; Braga, J. L.; Oliveira, A. P.; Passos, F. J. V. A Educação em Ambientes Virtuais: Proposição de Recursos Computacionais para Aumentar a Eficiência do Processo Ensino-Aprendizado. In: Rev. Bras. de Informática na Educação. V. 19. N.2. pp.42-55. 2011.

Lindström, P.; Gulz, A.; Haaket, M.; Sjöden, B. Match and Mismatching Between the Pedagogical Design Principles of a Math Game and the Actual Practices of Play. In: Journal of Computer Assisted Leraning. V. 27. pp. 90-102. 2011.

Liu, Y.; Han, S.; Li, H. Understanding the Factors Driving m-Learning Adoption: A Literature Review. In: Campus Wide Information Systems. V. 27. pp. 210-226. 2010.

Moreno, P. M.; Márquez, C. Y. The New Informatics Technologies in Education Debate. In: Comunications in Computer and Information Science. V. 19. pp. 291-296. 2008.

Oliveira, K. A.; Amaral M. A.; Domingos, G. R. A Avaliação do Uso de Objetos de Aprendizagem na Educação de Jovens e Adultos. In: Revista Brasileira de Informática na Educação. V. 19. N. 3. pp. 53-65. 2011.

Rachid, C. L.; Ishitani, L. M-Tutorial: Ferramenta de Autoria para Desenvolvimento de Tutoriais Voltado para o m-Learning. In: Rev. Bras. de Informática na Educação. V. 20. pp. 17-31. 2012.

Ross, J. A; Bruce, C. D; Sibbald, T. M. Sequencing Computer-Assisted Learning of Transformation of Trigonometric Functions. In: Teaching Mathematics Applications. V. 30. pp. 120-137. 2011.

Silva Júnior. MobileMech: Um Software Educacional para o Ensino de Mecâminca. Monografia de Final de Curso em Ciência da Computação. Universidade Federal de Lavras. 74p. 2013.

Tatnall, A.; Leonard, R. Purpose-Built Educational Computers in the 1980s: The Australian Experience. In: Adv. in Inform. and Communication Technology. V.325. pp.101-111. 2010.

Uzunboylu, H.; Cavus, N.; Ercag, E. Using Mobile Learning to Increase Environmental Awareness. In: Computers and Education. V. 52. pp. 381-389. 2009. 